\title{
Immunoglobulin G-induced Single Ionic Channels in Human Alveolar Macrophage Membranes
}

Deborah J. Nelson, Elizabeth R. Jacobs, John M. Tang, Janice M. Zeller, and Roger C. Bone

Departments of Physiology, Medicine, Medical Nursing, and Immunology/Microbiology, Rush Presbyterian St. Luke's Medical Center, Chicago, Illinois 60612

\begin{abstract}
While it is well known that the engagement of IgG Fc receptors on the macrophage surface triggers a number of cellular responses, including particle ingestion, secretion, and respiratory burst activity, the mechanism of signal transmission following ligand binding remains poorly understood. To acquire more data in this area, we studied the electrical properties of the macrophage membrane and its response to oligomeric immunoglobulin G (IgG) using the patch-clamp technique on human alveolar macrophages that were obtained by bronchoalveolar lavage and maintained in short-term tissue culture. The results showed that cell resting potentials, as determined from wholecell tight seal recordings, increased from $-15 \mathrm{mV}$ on the day of plating to $-56 \mathrm{mV}$ after the first day in culture and remained stable at this hyperpolarized level. Macrophages revealed an input resistance of $3.3 \mathrm{G} \Omega$, independent of age in culture. Extracellular application of heat-aggregated human IgG to cells voltage-clamped at $-70 \mathrm{mV}$ resulted in peak inward currents of $\sim 470 \mathrm{pA}$. We identified an IgG-dependent, nonselective channel in both cell-attached and isolated membrane patches, with a unitary conductance of $\sim 350 \mathrm{pS}$ and a predominant subconductance level of $235 \mathrm{pS}$ in symmetrical $\mathrm{NaCl}$ solutions. Single channel open times were observed to be in the range of seconds and, in addition, were dependent upon membrane voltage. Channel opening involved transitions between a number of kinetic states and subconductance levels. Channel events recorded in cell-attached patches showed characteristic exponential relaxations, which implied a variation in membrane potential as a result of a single ion channel opening. These data suggest that the IgG-dependent nonselective cation channel that we have characterized may provide the link between Fc receptor engagement and subsequent cellular activation.
\end{abstract}

\section{Introduction}

The alveolar macrophage represents a major cellular host defense mechanism against infectious agents and particulate materials that reach the terminal airways. The internalization of IgG-coated particles and immune complexes by the macrophage is often linked to the release of biologically active substances including neutral proteases (1), lysosomal enzymes

Address reprint requests to Dr. Nelson at her present address: Department of Medicine, Cardiology, University of Chicago, Hospital Box 249, 5841 S. Maryland Ave., Chicago, IL 60637.

Received for publication 28 November 1984 and in revised form 12 April 1985.

J. Clin. Invest.

(C) The American Society for Clinical Investigation, Inc. 0021-9738/85/08/0500/08 \$1.00

Volume 76, August 1985, 500-507
(2), arachidonic acid metabolites (3), and reactive oxygen products (4), presumably through receptor-ligand interactions. The mechanisms with which cells translate ligand binding to specific membrane receptors into the internal messages that direct phagocytosis or secretion remains unclear.

Recently, the technical development of the extracellular patch clamp has made it possible to examine the electrical currents that flow through single ionic channels as they open and close as a result of membrane receptor-ligand binding reactions. The technique uses a fire-polished glass micropipette pressed against a cell surface that eventually forms an electrically and chemically tight seal between the phospholipids of the membrane and the electrode glass. This allows one to control or clamp the voltage across the small patch of membrane (on the order of a few square microns in area) isolated by the pipette. The combination of the tight seal and the small membrane area permits the measurement of the passive flow of electrical current through individual membrane channels in the isolated patch of membrane $(5,6)$.

The isolation and incorporation of murine macrophage IgG Fc receptors into planar bilayers, and the observation that the reconstituted FCR functions as a ligand-dependent ion channel (7) has suggested the extracellular patch clamp as an appropriate way to examine the electrophysiological consequences of surface membrane exposure to immunoglobulin complexes. The existence of an IgG-dependent ion channel in intact phagocytic membranes could then provide the transmission link between surface membrane binding reactions and subsequent cellular phagocytic and inflammatory responses.

In the present study, which examines the whole-cell currents elicited by the application of heat-aggregated IgG, we attribute the IgG-induced conductance change to the presence of IgGdependent ionic channels. This paper will describe an immunoglobulin-dependent nonselective cation channel recorded from intact alveolar macrophage membranes, with an open state dependent on membrane voltage. The channel is characterized by a large unit conductance $(350 \mathrm{pS})$ with a number of subconductance states.

\section{Methods}

Specimen collection and cell culture. The project was approved by the human experimentation committee of Rush Presbyterian St. Luke's Medical Center with informed consent obtained. The subjects included men and women adult patients-smokers and nonsmokers-scheduled for bronchoscopy. After standard preoperative preparation and local airway anesthesia with $1 \%$ lidocaine hydrochloride, bronchoalveolar lavage specimens were collected in the usual manner (8) from the wedged position in the subject's right middle lobe or lingula. Lavage fluid was passed through a Nitex nylon mesh filter that excluded particles $>60 \mu \mathrm{m}$ in diameter and was then centrifuged. After the supernatant fluid was removed and the cell pellet was resuspended in culture medium that contained serum, cell counts were performed using a hemacytometer. Average yields ranged from 5 to $10 \times 10^{6}$ 
cells per subject. Differential cell counts were determined on wet mounts using neutral red dye exclusion as a basis for distinguishing between respiratory lymphocytes and alveolar macrophages. Cultures routinely used for electrophysiological experiments contained $>95 \%$ alveolar macrophages.

Cells were cultured on uncoated $35-\mathrm{mm}$ plastic tissue culture dishes (Falcon Labware, Oxnard, CA) at a density of $1 \times 10^{5}$ cells/ dish in minimum essential culture medium (Gibco Laboratories, Inc., Grand Island, NY) supplemented with 5\% fetal calf serum (Biologos, Naperville, IL) and 1\% penicillin-streptomycin (Gibco Laboratories). After a 1- to 2-h adherence, macrophage monolayers were washed with serum-free medium to remove all nonadherent contaminants and then incubated again in serum-containing medium at $37^{\circ} \mathrm{C}$ in a humidified atmosphere of $5 \% \mathrm{CO}_{2}$ in air. They remained in tissue culture for $\sim 1$ wk following initial harvesting and were used for electrophysiological experiments throughout the culture period. Experiments were performed on cells rounded in shape and estimated at 20-30 $\mu \mathrm{m}$ in diameter. All experiments were carried out at room temperature.

Electrophysiology. Single channel and whole-cell recordings from human macrophage membranes in tissue culture were obtained using the techniques of Hamill et al. (6). The dish with the cultured cells was placed in a chamber on the movable stage of an inverted Leitz microscope equipped with phase-contrast optics. Experiments were performed on whole cells and isolated membrane patches in both the cell-attached and excised inside-out (internal membrane surface facing the bathing solution) and outside-out (external membrane surface facing the bathing solution) configurations. Recording pipettes were formed from soda lime glass (Blue-Dot Hematocrit Glass; Fisher Scientific Corp., Pittsburgh, PA) using a vertical puller in a three stage process. Pipettes were coated with Sylgard 184 (Dow-Corning, Midland, MI) and fire-polished to a final tip diameter of $\sim 0.5 \mu \mathrm{m}$ just before use. The patch-clamp amplifier was designed by Dr. Richard Levis, Rush Medical College, and incorporated a U430 Dual FET (Siliconix, Santa Clara, CA) input headstage.

Recording pipette solutions varied in ionic composition according to experimental protocol but generally contained a $144 \mathrm{mM}$ chloride salt buffered to a pH of 7.4 with Hepes. In whole-cell voltage-clamp experiments, the pipette solution contained $144 \mathrm{mM} \mathrm{KCl}, 1 \mathrm{mM}$ $\mathrm{CaCl}_{2}, 1 \mathrm{mM}$ EGTA, and $10 \mathrm{mM}$ Hepes. The bathing solution contained, unless otherwise specified, $140 \mathrm{mM} \mathrm{NaCl}, 5.4 \mathrm{mM} \mathrm{KCl}$, $2.0 \mathrm{mM} \mathrm{Ca}_{2} \mathrm{Cl}$, and $10 \mathrm{mM}$ Hepes. The selectivity of the currents was determined by replacing the bath $\mathrm{NaCl}$ with isosmolar amounts of choline chloride or tetraethylammonium chloride (TEA) ${ }^{1}$ in the case of the whole-cell experiments, and by replacing the pipette $\mathrm{NaCl}$ with $\mathrm{KCl}$ in the case of the single channel experiments.

The heat aggregated IgG was prepared from $10 \mathrm{mg} / \mathrm{ml}$ monomeric human immunoglobulin (Cutter Biological Laboratories, Berkeley, CA) according to the method of James et al. (9). Monomeric IgG was prepared by centrifuging human IgG $(180,000 \mathrm{~g})$ for $1 \mathrm{~h}$, removing the supernatant, and adjusting its protein concentration to $1 \mathrm{mg} / \mathrm{ml}$ in saline. Samples were used immediately or stored at $4^{\circ} \mathrm{C}$ for up to $1 \mathrm{~h}$.

Aggregated IgM was prepared from $1 \mathrm{mg} / \mathrm{ml}$ human immunoglobulin (Miles Laboratories, Inc., Elkhart, IN) in phosphate-buffered saline by heating at $63^{\circ} \mathrm{C}$ until the point of opalescence $(60 \mathrm{~min})$. Unaggregated human IgM was used at a concentration of $0.1 \mathrm{mg} / \mathrm{ml}$.

Microperfusion system. Immunoglobulin was applied to alveolar macrophage membranes using a pneumatic microperfusion system. A fire-polished glass pipette fashioned on a microforge to a tip diameter of $\sim 2 \mu \mathrm{m}$ was filled with a solution of immunoglobulin and fitted to a syringe. Immunoglobulin application was controlled manually via the syringe with the pipette placed at a distance of $\sim 75 \mu \mathrm{m}$ from the target cell. This system was also used to apply immunoglobulin to outside-out patches.

Data analysis. Single channel and whole-cell currents were recorded on analogue tape with a bandwidth of DC-5 kHz. Signals from single

1. Abbreviations used in this paper: TEA, tetraethylammonium chloride. channel current recordings were low pass filtered at $2.0 \mathrm{kHz}$ (4-pole Bessel response) and then sampled at $250 \mu$ s per point before they were transferred to a digital tape for analysis. Single channel data was displayed, plotted, and analyzed using an automated pattern recognition program (10).

Where a multiple number of experiments were performed for a given experimental condition, values are reported as the mean \pm SEM with the number of experiments in parentheses.

\section{Results}

Basic electrophysiological characteristics. Macrophage resting potentials, measured in whole-cell experiments as the steady state potential at which no current flows, were observed to be a function of age in culture. On the day of culture plating, cells were uniformly depolarized with resting potentials of $-15 \pm 3 \mathrm{mV}(n=14)$. In general, membrane potentials increased significantly after the first culture day to $-55.6 \pm 4 \mathrm{mV}(n$ $=33$ ) and remained stable at this hyperpolarized level. In 27 cells, the average input resistance was $3.3 \pm 0.4 \mathrm{G} \Omega$.

IgG-dependent activation of inward current. Fig. 1 illustrates the inward current recorded from a human alveolar macrophage in the whole-cell configuration following the application of human heat-aggregated IgG to a cell voltage clamped at -70 $\mathrm{mV}$. Immunoglobulin was applied from a microperfusion pipette located $\sim 75 \mu \mathrm{m}$ from the voltage-clamped cell. A $1 \mathrm{mg} / \mathrm{ml}$ solution of $\mathrm{IgG}$ in standard $\mathrm{Na}^{+}$saline, used to fill the pipette, was applied to the cell by means of a continuous pressure ejection system. The IgG-induced peak current response varied from cell to cell, but, in general, ranged from 200 to $800 \mathrm{pA}$ (with a mean value of $468 \pm 84 \mathrm{pA}$ [6]). In seven experiments, the IgG-induced currents showed spontaneous decline, decaying to base-line levels within seconds, as seen in Fig. $1 A$, which shows a current record from a cell on

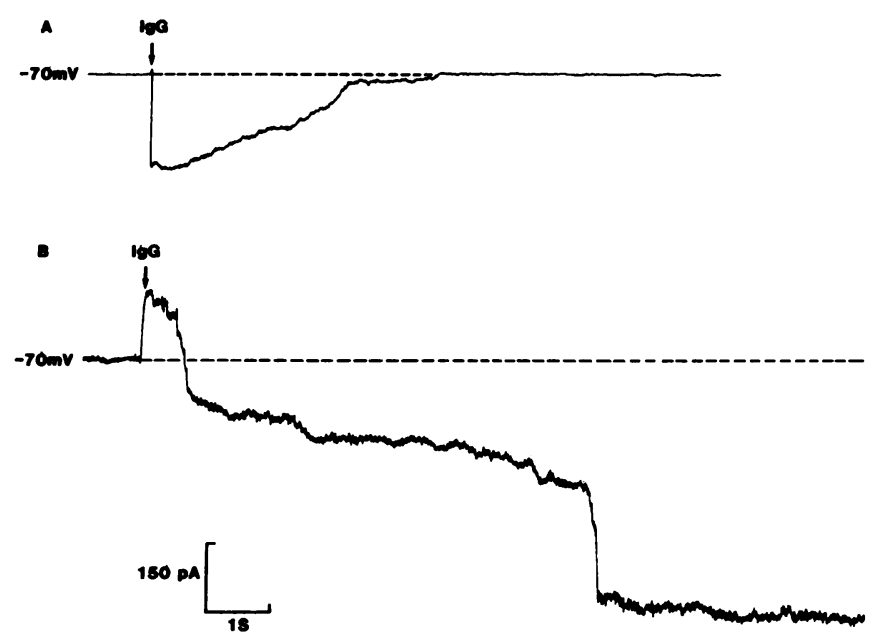

Figure 1. Whole-cell currents recorded from alveolar macrophages. Currents were elicited by microperfusing the cells with $1 \mathrm{mg} / \mathrm{ml} \mathrm{IgG}$ from a second micropipette placed $\sim 75 \mu \mathrm{m}$ distant from the voltageclamped cell. The pipette filling (whole-cell internal) solution contained $144 \mathrm{mM} \mathrm{KCl}, 1 \mathrm{mM} \mathrm{CaCl} 2,1 \mathrm{mM}$ EGTA, and $10 \mathrm{mM}$ Hepes. The bath solution was the standard high $\mathrm{Na}^{+}$. saline. Cells were voltage-clamped at $-\mathbf{7 0} \mathrm{mV}$ during $\mathrm{IgG}$ application. The initiation of IgG perfusion is marked by the arrow. Inward currents are plotted as downward deflections. Data was filtered at $500 \mathrm{~Hz}$. The dotted lines mark the current level before immunoglobulin perfusion. $(A)$ IgG-induced current obtained from a cell after $24 \mathrm{~h}$ in culture. (B) IgG-induced current obtained from a cell after $4 \mathrm{~d}$ in culture. 
the first day in culture. We usually observed a current response similar to that in Fig. $1 A$; however, in four experiments there was no visible current decay after maximum current activation, as can be seen in the current record of Fig. $1 B$ made from a cell on the fourth culture day. The step increase in inward current that is prominent in Fig. $1 B$ is not artifactual and could be observed frequently in the absence of spontaneous current decay. Although there are many explanations that could account for this phenomenon, one interesting possibility could be a time-dependent receptor aggregation leading to a delay in maximal current activation. Before inward current activation, it was common to observe a transient outward current of variable duration and amplitude directly after IgG perfusion, as can be most clearly seen in Fig. $1 \mathrm{~B}$. This could be due to the rapid activation of a calcium-dependent potassium conductance observed in patch-clamp studies on monocytederived macrophage membranes (11) that precedes the slower developing IgG-induced inward current. IgG-induced wholecell currents were studied in a total of 24 cells, of which six cells showed no response, 10 cells showed currents of rapid onset, and eight cells showed currents of delayed onset following IgG application. Inward currents could not be induced by the application of monomeric $\mathrm{IgG}(1 \mathrm{mg} / \mathrm{ml}$; nine experiments), heat-aggregated IgM $(1 \mathrm{mg} / \mathrm{ml}$; three experiments), or native, unaggregated IgM $(0.1 \mathrm{mg} / \mathrm{ml}$; three experiments).

Successive applications of IgG produced peak currents of decreasing amplitude (see Fig. $2 A$ ), suggesting a process of receptor desensitization. Desensitization occurred throughout a wide concentration range of applied $\operatorname{IgG}(0.1 \mu \mathrm{g} / \mathrm{ml}$ to $1 \mathrm{mg} /$ ml). Receptor desensitization observed after successive applications of IgG coupled with spontaneous current decay made the detailed measurement of the selectivity of IgG-induced currents as obtained from the reversal potential in steady state current voltage plots impossible.

Selectivity of IgG-induced inward current. To investigate the selectivity of the IgG-induced current response, we replaced the $\mathrm{Na}^{+}$in the bathing solution with a solution containing either the impermeant cation choline or TEA. Fig. $2 A$ shows the results of an experiment using choline as a $\mathrm{Na}^{+}$replacement in the bathing solution. In cells voltage-clamped at $-70 \mathrm{mV}$ in which an impermeant cation was present in the bathing solution, we observed a reversal of the IgG-induced current, thus indicating that the conductance activated as a result of IgG application was nonselective for cations allowing for an influx of $\mathrm{Na}^{+}$as well as an efflux of $\mathrm{K}^{+}$. Fig. $2 B$ illustrates the results of an experiment using TEA as a $\mathrm{Na}^{+}$substitute in the bathing solution. IgG-induced currents appeared to be $\mathrm{K}^{+}$ selective only in the absence of $\mathrm{Na}^{+}$. It should be noted here that cell resting potentials in solutions containing choline and TEA as $\mathrm{Na}^{+}$substitutes were consistently depolarized $(-20$ $\mathrm{mV}$ [2] in TEA and $-36 \pm 9 \mathrm{mV}$ [3] in choline containing bathing solutions).

Single channel experiments. To resolve the IgG-induced current response at the single channel level, we performed cell-attached and excised patch experiments on macrophages. In cell-attached patches in which IgG was included in the internal pipette solution, we observed the activation of a large conductance channel appearing 2-3 min after seal formation. High resistance seal formation was impaired when $\operatorname{IgG}$ at concentrations $>5 \mu \mathrm{g} / \mathrm{ml}$ was present in the pipette solution. The IgG single channel current response was investigated in a total of 70 membrane patches, $70 \%$ of which showed a response. We have characterized channel conductance, selectivity, and kinetics using a total of nine membrane patches from cells whose age in culture ranged from 0 to $5 \mathrm{~d}$. In a total of 12 excised and on-cell membrane patches where IgG was excluded from the patch pipette solution, we were unable to observe channel activity that was similar in conductance or selectivity to that obtained in the presence of IgG.

Fig. $3 \mathrm{~A}$ shows a representative IgG-induced single channel current recorded from a macrophage membrane in the cellattached configuration. Currents in cell-attached patches revealed characteristic exponential relaxations representing the distortion of a single channel current by the network formed
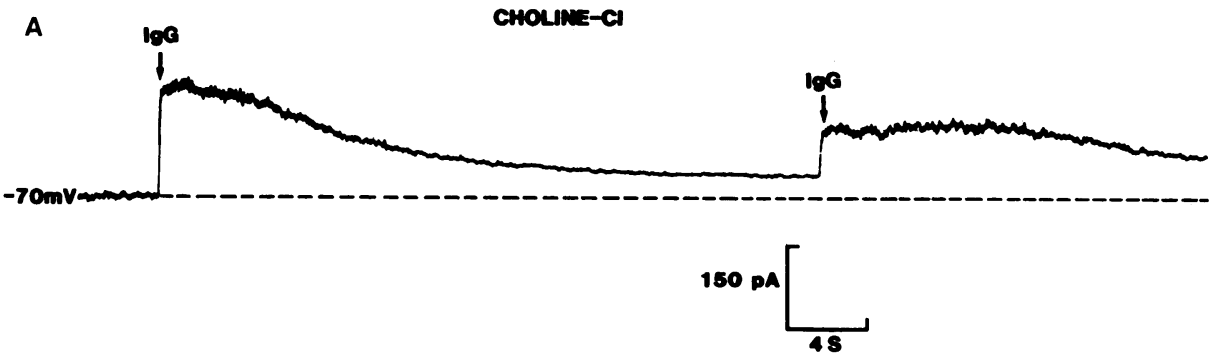

B

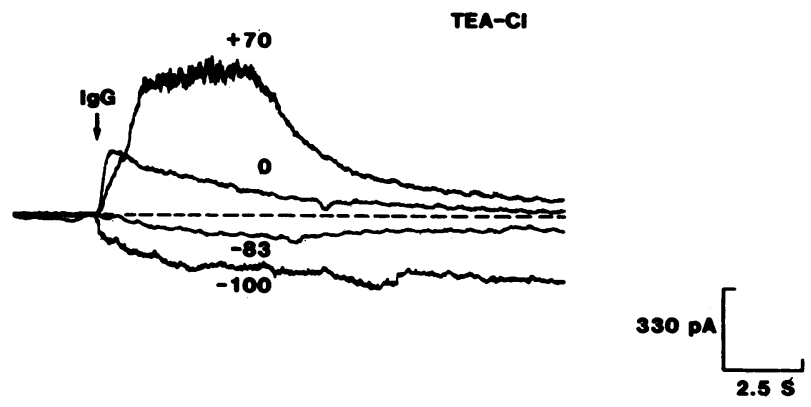

Figure 2. IgG-induced whole-cell voltage-clamp currents in the presence of $144 \mathrm{mM}$ external choline and TEA. $(A)$ The bathing solution $\mathrm{Na}^{+}$in this experiment was replaced with the impermeant cation choline, which resulted in a reversal of the current (efflux of $\mathrm{K}^{+}$) through the IgG-induced conductance pathway. The phenomenon of current desensitization after sequential applications of IgG can also be noted in this record. $(B)$ Time course of IgG-induced currents recorded from a different cell at the membrane potentials indicated. Current traces were recorded after sequential applications of IgG in a bathing solution, in which the $\mathrm{Na}^{+}$was isosmotically replaced with TEA. Membrane potentials were stepped from a holding potential of $0 \mathrm{mV}$ in the following sequence: $+70,0,-83$, and -100 . It must be assumed that successive IgG-induced peak currents were attenuated due to the phenomenon of receptor desensitization. 


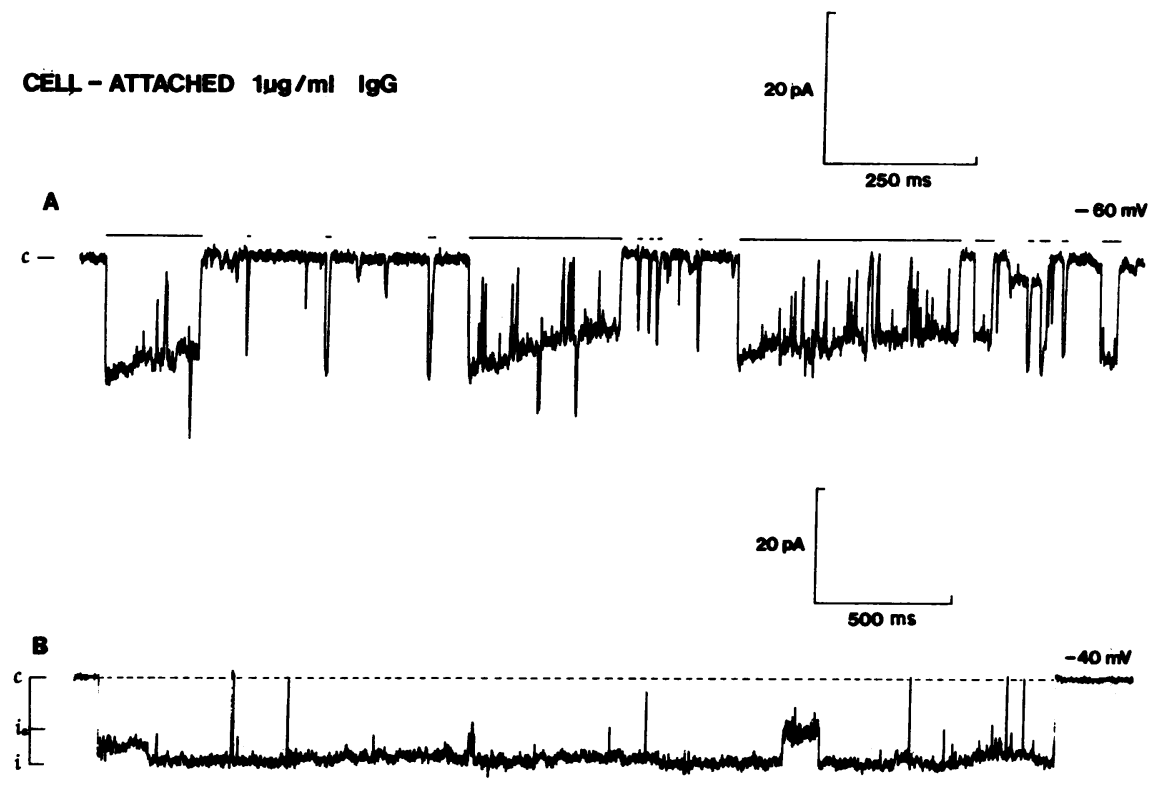

Figure 3. IgG-induced single channel currents in cell-attached patches. Bath solutions contained standard high $\mathrm{Na}^{+}$saline. In this figure, as in all following figures, the $c$ to the left of each trace marks the closed state current level, while $i$ and $i_{s}$ mark the open or fully conducting state and the subconductance states, respectively. Inward currents are plotted as downward deflections. $(A) \mathrm{IgG}$-induced currents with long relaxations during channel openings, showing that a single open channel can depolarize the cell's resting potential. The solid bars above the current record mark IgG channel openings. The pipette applied potential in this record hyperpolarized the membrane patch by $60 \mathrm{mV}$ with respect to the cell's resting potential. The pipette-filling solution was $144 \mathrm{mM} \mathrm{KCl}, 10 \mathrm{mM}$ Hepes, and 1 $\mathrm{mM} \mathrm{CaCl}_{2}$. (B) IgG-induced current showing no distortion. The pipette solution in this case was $144 \mathrm{mM} \mathrm{NaCl}$ and $10 \mathrm{mM}$ Hepes. Pipette solutions in both $A$ and $B$ contained $1 \mu \mathrm{g} / \mathrm{ml}$ IgG. of the parallel combination of the membrane resistance and capacitance (see Fenwick et al. [12]). When the cell's input impedance decreased, as was the case when the resting potential depolarized, square currents without associated relaxations could be observed in cell-attached patches, as indicated in Fig. $3 \mathrm{~B}$. Evidence for cellular depolarization came from the fact that inward currents were not observed in the absence of a pipette applied potential.

IgG-dependent channel characterization was approached from two separate aspects: $(a)$ determination of the magnitude and selectivity of the ion conductive pathway; and (b) measurement of channel open times and associated voltage dependence with a description of the kinetic inhomogeneity within a single channel opening.

Magnitude and selectivity. Fig. 4 illustrates representative patch-clamp current recordings of the IgG-induced channel at different membrane potentials. The record was taken from an inside-out patch in which the pipette solution contained the standard high $\mathrm{Na}^{+}$saline and $1 \mu \mathrm{g} / \mathrm{ml}$ heat-aggregated IgG. Fig. 4 shows that channel open time is a function of membrane
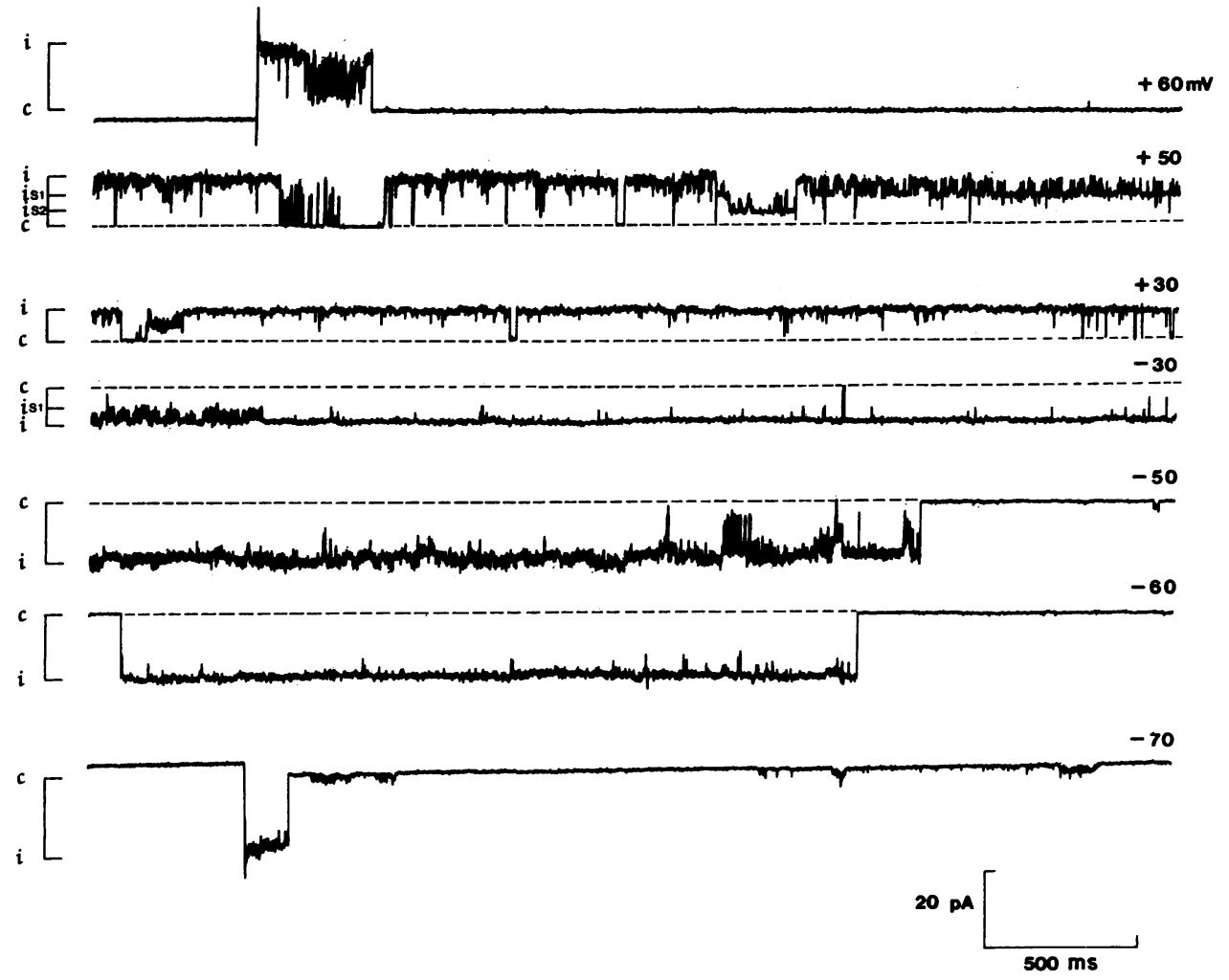

Figure 4. Voltage dependence of IgG-dependent single channel currents recorded from an alveolar macrophage. The recordings were obtained from an excised inside-out (internal membrane surface facing the bathing solution) patch where the IgG concentration within the pipette was $1 \mu \mathrm{g} / \mathrm{ml}$ and both bath and pipette contained the standard $\mathrm{Na}^{+}$saline. Data wère filtered at $1 \mathrm{kHz}$ and sampled at $500 \mu \mathrm{s} /$ point. Potentials are expressed as the potential at the intracellular surface of the membrane patch minus that in the bath. The potential was stepped from a holding potential of $0 \mathrm{mV}$ to the value given above each trace. The dotted lines indicate the closed state current level as indicated to the left of each record. The current traces for -70 and $+60 \mathrm{mV}$ differ from the other traces in that the current level at $0 \mathrm{mV}$ applied potential is shown at the beginning of each trace. 
potential in which the probability of finding the channel in the open state decreases at hyperpolarized potentials. Channel inactivation could be observed at both hyperpolarized and depolarized potentials greater than $\sim 60 \mathrm{mV}$ in excised patches where the internal $\mathrm{Ca}^{++}$concentration was increased to $2 \mathrm{mM}$, which is significantly greater than cytoplasmic levels. In such cases, channel openings were linked to the applied voltage pulse before closure (e.g., +60 and $-70 \mathrm{mV}$ in Fig. 4).

As can be seen in the complex current records of Fig. 4, IgG-activated channels were characterized by the presence of numerous open or subconductance states (see current recordings at $+50,+30$, and $-30 \mathrm{mV}$ in Fig. 4). The probability of observing subconductance levels or multiple open states was higher at more depolarized membrane potentials. Channel activation to the fully conductive state was preceded by a characteristic transition through a number of subconductance states as shown in Fig. 5.

Fig. 6 shows the ionic selectivity of the channel determined from current voltage plots. Single channel conductance calculated from the linear region of the current voltage curve in symmetrical $\mathrm{Na}^{+}$solutions was $352 \pm 20 \mathrm{pS}$ (3) with a prominent subconductance state of $235 \pm 4.7 \mathrm{pS}(3)$. A secondary subconductance state of $160 \mathrm{pS}$ was seen in the experiment of Fig. $6 \mathrm{~A}$. Single channel conductance in the presence of asymmetrical solutions was lower with a unitary conductance of $255 \pm 29 \mathrm{pS}$ (3) and subconductance of $156 \pm 1 \mathrm{pS}$ (2). In the experiment depicted in Fig. $6 \mathrm{~B}$, a secondary subconductance level of 84 pS was observed at highly depolarized potentials. In isolated patches, the reversal potential for both the full conductance and the associated subconductance states in the presence of a gradient for cations was $0 \mathrm{mV}$, thus establishing that the channel was nonselective for $\mathrm{Na}^{+}$and $\mathrm{K}^{+}$. Fig. $6, A$ and $B$, illustrates experiments in which both subconductance levels appeared over a wide voltage range, making the quantitation of the associated slope conductance possible. It was more often the case that both primary and secondary subconductance levels were apparent at only a few voltages throughout a voltage range as can be seen in Fig. 4, in which the primary subconductance level was prominent only at -30 and +50 $\mathrm{mV}$ and the secondary subconductance level was observable only at $+50 \mathrm{mV}$.

Channel open times and kinetic inhomogeneity. Channel open times varied considerably from experiment to experiment and could be in the range of seconds. Mean channel open times for the experiment illustrated in Fig. 4 are given in Table I. The probability of finding the channel in the open state decreased with increasing membrane hyperpolarization.

In addition, single channel events were characterized by the presence of numerous kinetic states within a single opening. Periods during which the channel was maximally open or closed were interspersed with periods in which the channel entered a rapid flickering state (Fig. 7, $A$ and $B$ ). Although too rapid to be resolved by our limited bandwidth, such flickering may involve transitions through a number of subconductance states.

\section{Discussion}

It was the aim of this investigation to determine whether the human alveolar macrophage Fc receptor functions as a liganddependent ion channel in intact cell membranes using extracellular patch-clamp recording techniques. The findings from whole-cell as well as single channel recordings have established that exposure of macrophage membranes to oligomeric IgG results in an inward $\mathrm{Na}^{+}$current mediated through the opening of nonselective cation channels of large conductance (350 pS in symmetrical $\mathrm{Na}^{+}$solutions), whose open state is a sensitive function of membrane voltage. In cells maximally stimulated with IgG, the observed mean inward current of $470 \mathrm{pA}$ would correspond to the opening of $\sim 27$ channels to their fully conductive state (calculated from a single channel conductance of $260 \mathrm{pS}$ in asymmetrical $\mathrm{Na}^{+}$solutions). Surface membranes show a reduced response to sequential applications of IgG, indicating the phenomenon of receptor desensitization.

The membrane resting potentials that we observed with whole-cell tight-seal recording techniques are significantly more negative than values previously reported in the literature with conventional microelectrode techniques (13-15), in which impalement shunts artifactually lower measured resting potentials. Similarly, the whole-cell input resistance values of 0.4 to $8 \mathrm{G} \Omega$ that we obtained were high compared with values reported in earlier electrophysiologic studies on macrophage membranes, which, again, is attributable to the absence of impalement shunt artifacts obtained using tight-seal recording techniques. They are in accord, however, with other more recent data obtained using tight-seal techniques $(11,16)$.

The complex cellular functions of secretion and phagocytosis are triggered following the binding of multivalent ligands, e.g., immune complexes, heat-induced aggregates, and antibodycoated particles to macrophage Fc receptors. Rabbit alveolar macrophages possess $2.0 \times 10^{6}$ receptors per cell that specifically bind the Fc portion of IgG (17). Surface receptors for IgG, with the highest affinity for the IgG $_{3}$ subclass, have also been confirmed on human alveolar macrophages (18). Binding of a monoclonal anti-Fc receptor antibody to isolated murine $\mathrm{Fc}$ receptors incorporated into planar bilayers forms cation selective ion channels (7). Young et al. (19) have further demonstrated in intact cells that the extent and duration of cellular depolarization after Fc receptor engagement is dependent upon the

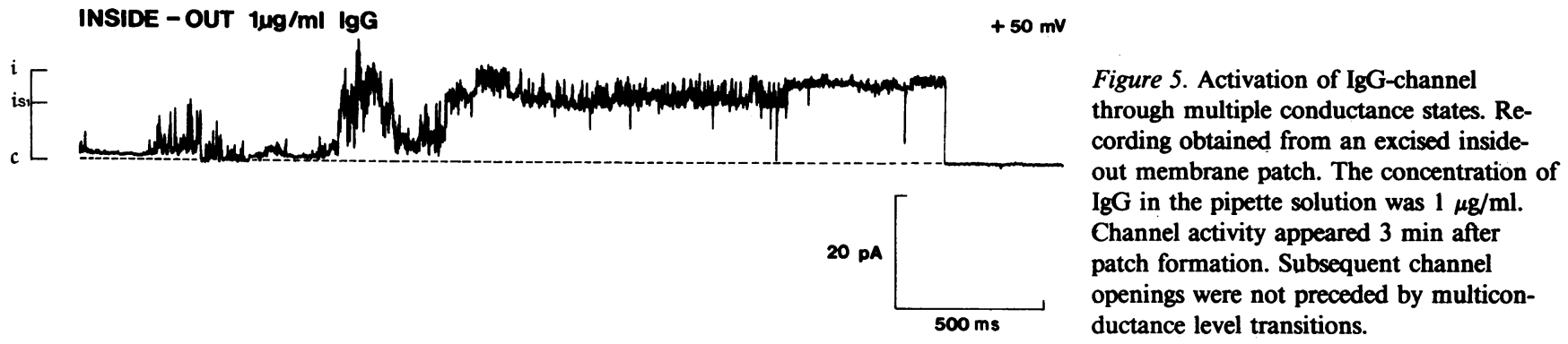



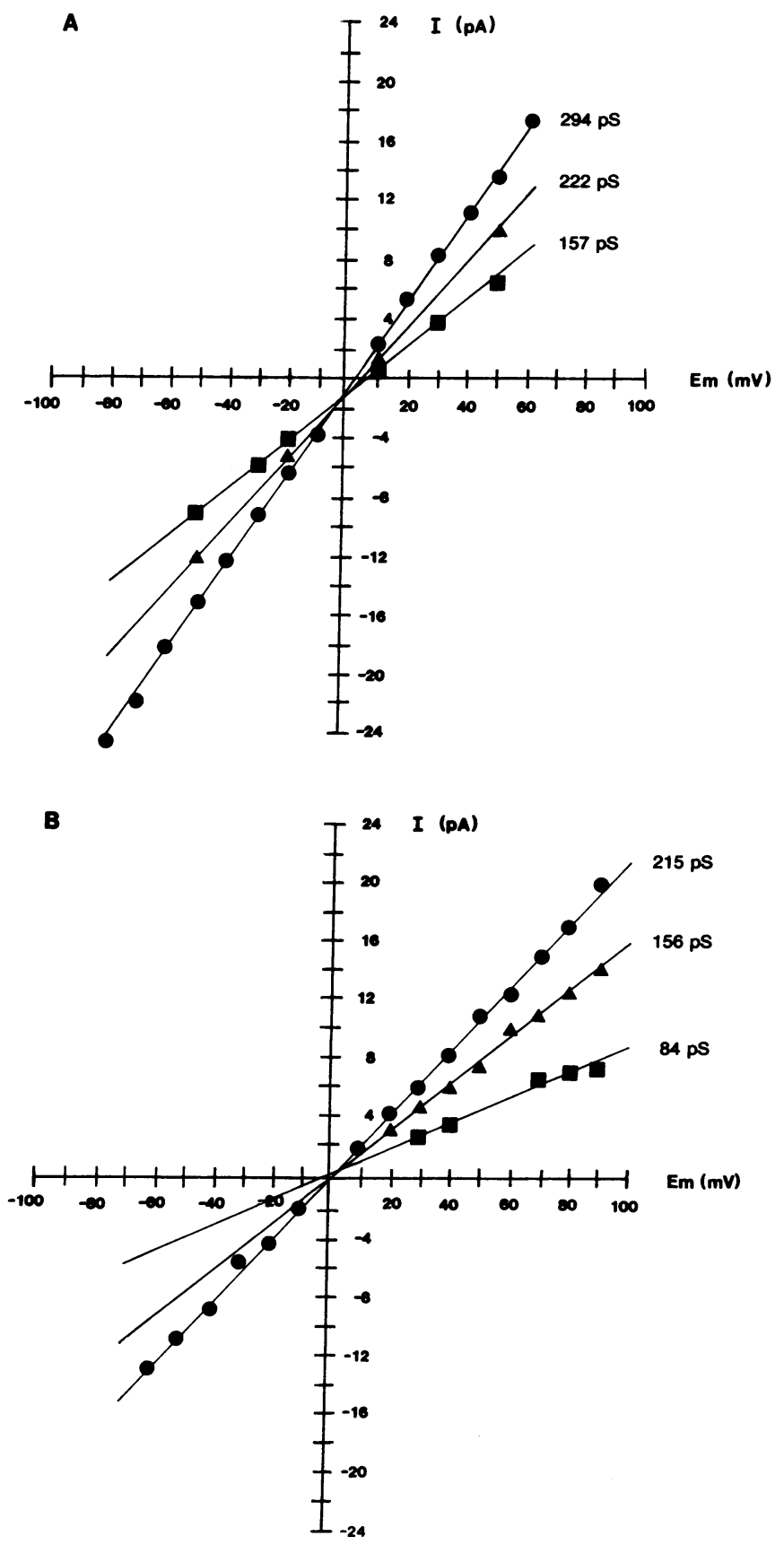

Figure 6. Single channel current-voltage curves from two excised membrane patches. $(A)$ IgG-channel current amplitude is plotted versus applied membrane potential. The filled circles represent current amplitudes obtained for the fully open state; triangles and squares correspond to amplitudes for the two major subconductance levels. Recordings were obtained from an excised outside-out (external membrane surface facing the bathing solution) membrane patch microperfused with $0.1 \mu \mathrm{g} / \mathrm{ml} \mathrm{IgG}$, in which both bath and pipette contained the standard high $\mathrm{Na}^{+}$saline. (B) Current amplitudes versus membrane voltage from an excised inside-out membrane patch (intracellular membrane surface facing the bathing solution), in which the pipette solution contained $144 \mathrm{mM} \mathrm{KCl}$ and $10 \mathrm{mM}$ Hepes in addition to $1 \mu \mathrm{g} / \mathrm{ml} \mathrm{IgG}$ and the bathing solution was the standard $\mathrm{Na}^{+}$saline. The closed circles represent current amplitudes for the full conductance state; the triangles and squares are values obtained for the two major subconductance states. Reversal potentials for all three conductance states were $\sim 0 \mathrm{mV}$. The solid lines represent linear regression analysis on the data points.
Table I. Voltage Dependence of Mean Open Time for the IgG-induced Channel

\begin{tabular}{lc}
\hline$V_{\mathrm{m}}$ & Mean open time \\
\hline$m V$ & $m s$ \\
+60 & 958 \\
+50 & 2,062 \\
+30 & 4,600 \\
-30 & 3,083 \\
-50 & 918 \\
-60 & 140 \\
-70 & 26
\end{tabular}

Channel open times are given for the experiment in Fig. 4 and were determined as simple arithmetic means due to the small number of events obtained during each voltage record. $V_{\mathrm{m}}$, membrane potential.

degree of ligand multivalency. These observations using intact cells and artificial membranes support our observation that the macrophage IgG Fc receptor is a ligand-dependent ion channel.

Although no single channel analysis has been made to date concerning the effects of specific ligands involved in secretory, chemotactic, or other cellular functions of macrophages, patchclamp current recordings of many spontaneously active ion channels have recently been obtained from a number of cells in the immune system. Fukushima et al. (20) demonstrated a voltage-dependent $\mathrm{Ca}^{++}$current in myeloma and hybridoma cells derived from B lymphocytes, while Fukushima et al. (21) have observed a $\mathrm{K}^{+}$current that is not $\mathrm{Ca}^{++}$-activated in cytotoxic $\mathrm{T}$ lymphocytes from the mouse, which the authors suggest is associated with the lethal hit of the cytotoxic reaction. DeCoursey et al. (22) and Matteson and Deutsch (23) describe a voltage-activated $\mathrm{K}^{+}$current in human $\mathrm{T}$ lymphocytes similar to the delayed rectifier $\mathrm{K}^{+}$channel that gives rise to repolarization in neurons. Their results strongly suggest that modulation of $\mathrm{K}^{+}$channel gating by mitogens may trigger subsequent cellular events culminating in cell division. Gallin $(11,24)$ has recently noted the presence of two separate single channel $\mathrm{K}^{+}$conductances in the macrophage membranes, one of which is the ubiquitous $\mathrm{Ca}^{++}$-activated $\mathrm{K}^{+}$ channel, and the other is likely to represent the inward rectifier. Finally, Schwarze and Kolb (25) have observed a voltagedependent anion channel in mouse peritoneal macrophages with a conductance of $340 \mathrm{pS}$ and a prominent subconductance of $210 \mathrm{pS}$.

IgG-induced single channel currents, which we observed in cell-attached membrane patches (but not in excised patch recordings), frequently revealed exponential relaxations, implying a change in membrane potential resulting from a single channel opening. Fenwick et al. (12) have demonstrated in patch-clamp studies of bovine chromaffin cells that when the impedance of the cell and that of a single open channel are comparable, then the activity of the single channel can change the membrane potential across the whole cell. The magnitude of the decay in IgG-dependent single channel currents, which reflected a change in cell membrane potential, varied from cell to cell, but, nonetheless, provided evidence that a single channel opening was sufficient to depolarize the entire cell. In the example given in Fig. $8 \mathrm{~A}$, a decay of $5.6 \mathrm{pA}$ was observed 

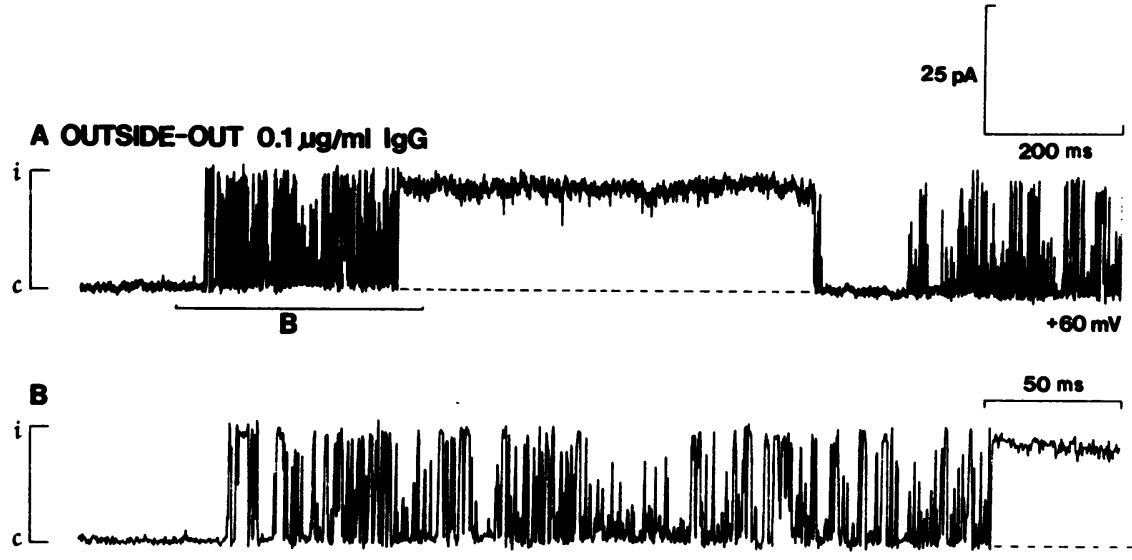

Figure 7. IgG channel kinetic heterogeneity. This record was obtained from an outside-out membrane patch microperfused with $0.1 \mu \mathrm{g} /$ $\mathrm{ml}$ IgG, in which both bath and pipette contained the standard $\mathrm{Na}^{+}$saline. $(A)$ Current recording showing the presence of both the fully open and the flickering states that occur during a given channel opening. Note, that unlike the fast transitions through multiple conductance states that were observed to precede full channel activation (see Fig. 5), flickering in this record seems to fluctuate primarily between the fully open and the fully closed state. $(B)$ Expanded portion of the upper trace marked by the bar. The kinetic process was frequently too rapid to resolve. during a single channel opening (represented by a closing of the switch in Fig. 8 B).

In the equivalent circuit in Fig. $8 B, g$ (Siemens) and $c$ (Farads) represent, respectively, the total conductance and total capacitance of the cell membrane not covered with the patch pipette. The small amount of conductance and capacitance resulting from the membrane in the patch is neglected. When the switch is open (channel is closed) the cell has a resting voltage $E_{\mathrm{m}}$ (volts). When the switch is closed, current flows through the single channel conductance, $\gamma_{c}$ (Siemens). The net driving force for current flow is the pipette voltage, $V_{\mathrm{p}}$ (volts), less the diffusion potential for the channel, $E_{c}$ (volts), less the cell voltage, which will no longer equal $E_{\mathrm{m}}$ because of the current flowing through $g$.

The equations describing the current flow before and during a channel opening according to the equivalent circuit as modeled in Fig. $8 \mathrm{~B}$ are

$i_{0}=\gamma_{c}\left(V_{\mathrm{p}}-E_{c}-E_{\mathrm{m}}\right)$,

and

$i_{\mathrm{ss}}=\frac{\left(V_{\mathrm{p}}-E_{c}-E_{\mathrm{m}}\right)\left(\gamma_{c} g\right)}{\gamma_{c}+g}$,
A

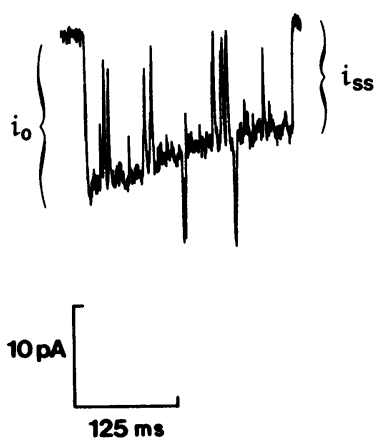

B

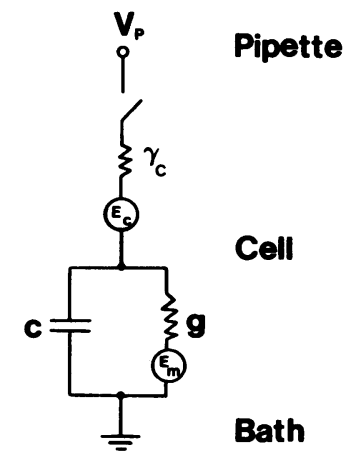

Figure 8. Interaction of single channel currents with the cell RC network in cell-attached patches. $(A)$ Inward single channel event exhibiting a pronounced current relaxation. The channel opening was taken from the current trace shown in Fig. $3 \mathrm{~A}$. The pipette applied potential in this recording hyperpolarized the membrane patch by 60 $\mathrm{mV}$. (B) The equivalent circuit of the patch of membrane isolated by the pipette and the cell. where $i_{0}$ and $i_{s s}$ refer to the initial and steady state single channel current amplitudes during an opening event. The single channel conductance, $\gamma_{c}$, and diffusion potential, $E_{c}$, are determined independently in an excised patch $\left(\gamma_{c}=280\right.$ $\mathrm{pS}$ and $E_{c}=0 \mathrm{~V}$ for the IgG-dependent channel of Fig. 8).

Taking the ratio of the initial to the steady state current value gives

$\frac{i_{0}}{i_{s s}}=\frac{\gamma_{c}+g}{g}$

Since $i_{0}$ and $i_{\mathrm{ss}}$ can be measured in Fig. $8 \mathrm{~A}$ and given the independently determined value of $\gamma_{c}$, we can determine from Eq. 3 that $g \simeq 520 \mathrm{pS}$.

From the steady state current equation, we can calculate a rough estimate of the change in membrane potential $\left(\Delta V_{m}\right)$ during a single channel opening:

$\Delta V_{\mathrm{m}}=\frac{i_{\mathrm{ss}}}{g}$

The membrane potential before channel opening in Fig. $8 \mathrm{~A}$ was calculated to be $20 \mathrm{mV}$ more negative than the steady state value during the opening of the channel. Thus, the droop in the open channel current is due to the change in driving force as the cell voltage changes from $E_{\mathrm{m}}$ to $E_{\mathrm{m}}+\Delta V_{\mathrm{m}}$ as the membrane capacitance charges.

The presence of a spectrum of subconductance levels that we observed in the IgG-activated channels was speculated to be the basis, in the observations of Jackson et al. (26), for the wide spread in channel current amplitudes of single complement-induced channels in antibody-coated skeletal muscle cells (using early low resolution single channel recording techniques). Analogous membrane channel fluctuations between a number of subconductance levels can be seen in artificial systems, e.g., hemocyanin (27), as well as more recent single channel recordings in intact biological membranes, e.g., muscle and epithelial (28-30). It is tempting to speculate that the subconductance levels that we noted in the immunoglobulin channel might be related to the degree of receptor aggregation, since the unit conductance observed for the oligomeric IgGinduced channel appears considerably larger than the unit conductance (60 pS in $1 \mathrm{M} \mathrm{KCl}$ ) observed for the reconstituted FcR channels activated by a monoclonal anti-FcR antibody in planar bilayers (7). Single channel open times and the presence of receptor desensitization in the artificial systems 
are remarkably similar to those observed in intact macrophage membranes.

The technique of extracellular patch clamping was applied to establish the existence of an ion channel in human alveolar macrophages membranes, the activity of which was a consequence of membrane exposure to complexed immunoglobulin. Both the unbound and the monomerically bound receptor form a nonconducting or closed channel, while the complex of multimeric IgG and a number of bound receptors form the open or conducting channel. We characterized an IgG dependent nonselective cation channel seen in both cell-attached and excised membrane patch configurations whose open state is voltage-dependent. The channel exhibited a number of kinetic and subconductance states. Whole-cell currents showed the phenomenon of receptor desensitization upon sequential exposure to IgG. We speculate that the complex cellular functions of phagocytosis and secretion may be initiated via the activity of this ligand-dependent ion channel.

\section{Acknowledgments}

The authors wish to express their gratitude to Dr. F. Sachs who provided a copy of the automated single channel analysis programs and Drs. R. Eisenberg, R. Levis, and R. Mathias for their many suggestions and critical reading of the manuscript.

This work was supported by U. S. Public Health Service grant NS18587 to Dr. Nelson and a grant from the Fry Foundation to Drs. Jacobs, Nelson, and Bone.

\section{References}

1. Unkeless, J. C., S. Gordon, and E. Reich. 1974. Secretion of plasminogen activator by stimulated macrophages. J. Exp. Med. 139: 834-850.

2. Dannenberg, A. M. 1968. Cellular hypersensitivity and cellular immunity in the pathogenesis of tuberculosis: specificity, systemic and local nature, and associated macrophage enzymes. Bacteriol. Rev. 32: 85-102.

3. Scott, W., J. Zrike, A. Hamill, A. J. Kempe, and Z. Cohn. 1980. Regulation of arachidonic acid metabolites in macrophages. $J$. Exp. Med. 152:324-335.

4. Baxter, M. A., R. G. Q. Leslie, and W. G. Reeves. 1983. The stimulation of superoxide anion production in guinea pig peritoneal macrophages and neutrophils by phorbol myristate acetate, opsonized zymosan and IgG-containing soluble immune complexes. Immunology. 48:657-665.

5. Neher, E., and B. Sakmann. 1976. Single-channel currents recorded from membrane of denervated frog muscle fibres. Nature (Lond.). 260:799-802.

6. Hamill, O. P., A. Marty, E. Neher, B. Sakmann, and F. J. Sigworth. 1981. Improved patch clamp techniques for high-resolution current recordings from cells and cell-free membrane patches. Pfluegers Arch. Eur. J. Physiol. 391:85-100.

7. Young, D. E., J. C. Unkeless, T. M. Young, A. Mauro, and Z. A. Cohn. 1983. Role for mouse macrophage IgG Fc receptor as ligand-dependent ion channel. Nature (Lond.). 306:186-189.

8. Hunninghake, G. W., J. E. Gadek, O. Kawanami, V. J. Ferrios, and R. G. Crystal. 1979. Inflammatory and immune processes in the human lung in health and disease: evaluation by bronchoalveolar lavage. Am. J. Pathol. 97:149-206.

9. James, K., B. Hansen, and H. Gewurz. 1981. Binding of C- reactive protein to human lymphocytes. II. Interaction with a subset of cells bearing the Fc receptor. J. Immunol. 127:2545-2550.

10. Sachs, F., J. Neil, and N. Barkakati. 1982. The automated analysis of data from single ionic channels. Pfluegers Archiv. Eur. J. Physiol. 395:331-340.

11. Gallin, E. K. 1984. Calcium- and voltage-activated potassium channels in human macrophages. Biophys. J. 46:821-825.

12. Fenwick, E. M., A. Marty, and E. Neher. 1982. A patch-clamp study of bovine chromaffin cells and of their sensitivity to acetylcholine. J. Physiol. (Lond.). 331:577-597.

13. Gallin, E. K., and J. I. Gallin. 1977. Interaction of chemotactic factors with human macrophages. Induction of transmembrane potential changes. J. Cell Biol. 75:277-289.

14. Dos Reis, G. A., P. M. Persechini, J. M. C. Ribeiro, and G. M. Oliveira-Castro. 1979. Electrophysiology of phagocytic membranes. II. Membrane potential and induction of slow hyperpolarizations in activated macrophages. Biochim. Biophys. Acta. 552:331-340.

15. Gallin, E. K., M. L. Wiederhold, P. E. Lipsky, and A. S. Rosenthal. 1975. Spontaneous and induced membrane hyperpolarization in macrophages. J. Cell. Physiol. 86:653-662.

16. Ypey, D. L., and D. E. Clapham. 1984. Development of a delayed outward-rectifying $\mathrm{K}^{+}$conductance in cultured mouse peritoneal macrophages. Proc. Natl. Acad. Sci. USA. 81:3083-3087.

17. Arend, W. P., and M. Mannik. 1975. Quantitative studies on IgG receptors on monocytes. In Mononuclear Phagocytes. R. Van Furth, editor. Blackwell Scientific, Oxford. 303-314.

18. Naegel, G. P., K. R. Young, and H. Y. Reynolds. 1984. Receptors for human IgG subclasses on human alveolar macrophages. Am. Rev. Respir. Dis. 129:413-418.

19. Young, D. E., J. C. Unkeless, H. R. Kaback, and Z. A. Cohn. 1983. Macrophage membrane potential changes associated with $\gamma 2 \mathrm{~b} /$

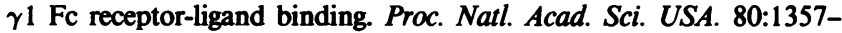
1361 .

20. Fukushima, Y., S. Hagiwara, and R. E. Saxton. 1984. Variation of calcium current during the cell growth cycle in mouse hybridoma lines secreting immunoglobulins. J. Physiol. (Lond.). 355:313-321.

21. Fukushima, Y., S. Hagiwara, and M. Henkart. 1984. Potassium current in clonal cytotoxic T lymphocytes from the mouse. J. Physiol. (Lond.). 351:645-656.

22. DeCoursey, T. E., K. G. Chandy, S. Gupta, and M. D. Cahalan. 1984. Voltage-gated $\mathrm{K}^{+}$channels in human $\mathrm{T}$ lymphocytes: a role in mitogenesis? Nature (Lond.). 307:465-468.

23. Matteson, D. R., and C. Deutsch. 1984. K channels in T lymphocytes: a patch clamp study using monoclonal antibody adhesion. Nature (Lond.). 307:468-471.

24. Gallin, E. K. 1984. Electrophysiological properties of macrophages. Fed. Proc. 43:2385-2389.

25. Schwarze, W., and H.-A. Kolb. 1984. Voltage-dependent kinetics of an anionic channel of large unit conductance in macrophages and myotube membranes. Pfluegers Arch. Eur. J. Physiol. 402:281-291.

26. Jackson, M. B., C. L. Stephens, and H. Lecar. 1981. Single channel currents induced by complement in antibody-coated cell membranes. Proc. Natl. Acad. Sci. USA. 78:6421-6425.

27. Latorre, R., O. Alvarez, G. Ehrenstein, M. Espinoza, and J. Reyes. 1975. The nature of the voltage-dependent conductance of the hemocyanin channel. J. Membr. Biol. 25:163-182.

28. Hamill, O. P., and B. Sakmann. 1981. Multiple conductance states of single acetylcholine receptor channels in embryonic muscle cells. Nature (Lond.). 294:462-464.

29. Auerbach, A., and F. Sachs. 1983. Flickering of a nicotinic ion channel to a subconductance state. Biophys. J. 42:1-10.

30. Nelson, D. J., J. M. Tang, and L. G. Palmer. 1984. Single channel recordings of apical membrane chloride conductance in A6 epithelial cells. J. Membr. Biol. 80:81-89. 